\title{
ESTUDIOS
}

\section{La educación para el desarrollo en la lucha contra la pobreza: aportes para el profesorado universitario'}

\author{
$M^{a}$ Luz Ortega Carpio, Antonio Sianes Castaño, $M^{a}$ Rosa Cor- \\ dón Pedregosa ${ }^{2}$
}

Resumen: Este artículo parte de la reflexión y práctica realizada por los autores en su desempeño académico, y trata de mostrar las posibilidades que la educación para el desarrollo aporta al ejercicio de la docencia y la investigación universitaria desde las claves de la lucha contra la pobreza. Para ello, en la primera parte del trabajo se detalla el modelo educativo que ofrece la educación para el desarrollo, sus dimensiones y ámbitos, así como la pertinencia de su presencia en el espacio universitario. En la segunda parte se muestran algunas herramientas y principios metodológicos empleados por la educación para el desarrollo, que tienen cabida en el actual Espacio Europeo de Educación Superior, y son susceptibles de facilitar el ¿̇ejercicio? de una pedagogía reflexiva, crítica y emancipadora por parte del profesorado universitario.

Palabras clave: Lucha contra la pobreza, Educación para el desarrollo, Universidad, Espacio Europeo de Educación Superior (EEES).

Fecha de recepción: II de mayo de 2012.

Fecha de admisión definitiva: 28 de noviembre de 2012 .

\footnotetext{
' Esta publicación recoge parte de la investigación 11-PR1-0451 realizada por el Grupo de Estudios en Desarrollo de la Universidad Loyola Andalucía y la Fundación ETEA para el Desarrollo y la Cooperación. Este proyecto ha sido financiado por la Agencia Española de Cooperación Internacional para el Desarrollo (AECID). El contenido es responsabilidad exclusiva de los autores y no refleja necesariamente la opinión de la AECID.

${ }^{2}$ Universidad Loyola Andalucía y Fundación ETEA para el Desarrollo y la Cooperación. Grupo de Estudios en Desarrollo, Córdoba.
} 
Education for development in the fight against poverty: input for university faculty

Abstract: This article derives from the reflections and experiences of the authors in their academic activities, and tries to show the possibilities that Education for Development offers in university teaching and research from the perspective of the fight against poverty. To do so, in the first part of our presentation, the educational model offered through Education for Development is set out in detail, along with its dimensions and scenarios, and the fact that it belongs in the university. The second part shows some of the tools and methodological principles used by Education for Development which fit into the current European Higher Education Area, and which are pertinent for facilitating the "exercise?" of thoughtful, critical and emancipating teaching criteria on the part of university teachers.

Key words: Fight against poverty, Education for Development, University, The European Higher Education Area (EHEA).

\section{L'éducation au développement dans la lutte contre la pauvreté: contribu- tion pour le corps professoral}

Résumé: Cetarticle fait partie de la réflexion et la pratique effectuée par les auteurs dans leur engagement académique et il essaie de montrer les possibilités que l'éducation pour le développement apporte à l'enseignement et à la recherche universitaires des clés de la lutte contre la pauvreté. Pour ce faire, dans la première partie du texte on présente le modèleéducatifqui assurel'éducation pour le développement, ses dimensions et domaines, ainsi que la pertinence de leur présence dans le domaine universitaire. La deuxième partie présente quelques outils et principes méthodologiques employées par l'éducation pour le développement, qui ont lieu dans l'espace européen de l'enseignement supérieur (EEES) et qui sont susceptibles de faciliter l'exercice $d^{\prime}$ une pédagogie réfléchissante, critique et émancipatrice des professeurs d'université.

Mots Clés: Lutte contre la pauvreté, éducation pour le dévelopement, université, Espace européen d'enseignement supérieur.

\section{Introducción}

A lo largo del último medio siglo, se ha venido construyendo en el ámbito del desarrollo y la cooperación una nueva disciplina que ha dado en llamarse Educación para el Desarrollo (ED). En los últimos años, la literatura sobre la misma ha sido bastante profusa, especialmente con los objetivos de avanzar en su conceptualización y de analizar el papel que los diferentes actores de los sistemas de cooperación y educativo estarían llamados a desempeñar en ésta. Sin embargo, los estudios que han centrado su atención en el rol que podría desempeñar la Universidad como institución han sido minoritarios, y residuales aquellos que se centran en el aporte capital que realiza el profesorado universitario al proceso de ED. 
Aunque en los últimos años la Universidad ha ratificado diversos compromisos en la materia: Estrategia de Cooperación Universitaria al Desarrollo, Código de Conducta de las universidades en materia de desarrollo, etc., el entorno académico aún no está propiciando un reconocimiento adecuado de esta labor, lo que a la larga podría comprometer el desempeño de una labor docente e investigadora implicada en la lucha contra la pobreza.

Sin embargo, la realidad nos muestra que, paralelamente al proceso de incidencia institucional iniciado para facilitar este reconocimiento, es cada vez más numeroso el profesorado que afronta el ejercicio diario de su función docente e investigadora desde las claves de la lucha contra la pobreza y la promoción de una mayor justicia y equidad global.

En nuestra experiencia universitaria hemos podido vivir en primera persona las posibilidades que aporta al proceso de ED el ejercicio de una docencia y una investigación universitaria comprometidas en la lucha contra la pobreza ${ }^{3}$, lo que ratifica nuestro convencimiento de que es preciso seguir incorporando activamente a la comunidad universitaria en el proceso de ED. Es por ello que, con el objetivo de animar y apoyar a otros docentes que quieran sumarse a este proceso, querríamos detener nuestra mirada en una serie de metodologías y enfoques que, recogidos y adaptados por la ED, se están mostrando como favorecedores del ejercicio de una pedagogía reflexiva, comprometida y liberadora.

A tal fin, el presente artículo se estructurará de la siguiente manera: en el primer apartado, nos detendremos en un análisis histórico de las distintas corrientes de ED para situar a la Universidad como un agente clave de su proceso transformador. En este apartado, nos haremos eco de algunas de las voces que claman por un posicionamiento más comprometido de la Universidad ante la realidad de la pobreza, y veremos cómo efectivamente la Universidad comienza a asumir dicho rol. En el segundo apartado, centraremos nuestra atención en el profesorado universitario, aportando algunos elementos, enfoques y metodologías que, independientemente del posicionamiento institucional de sus universidades al respecto, pueden facilitarle el ejercicio de una labor docente e investigadora desde estas claves de lucha contra la pobreza.

\footnotetext{
${ }^{3}$ De hecho, este artículo no sería posible sin el ejemplo personal y profesional de compromiso ético del colectivo de profesores que, actualmente, comparten con nosotros esta inquietud en la labor docente $\mathrm{e}$ investigadora en ETEA, Facultad de Ciencias Económicas y Empresariales, Córdoba.
} 


\section{Hacia una Educación para el Desarrollo en el espacio universitario}

\section{I. El devenir epistemológico de la Educación para el Desarrollo}

La educación, sin duda, brinda oportunidades a aquellos que nacen sin tenerlas. No en vano, el Programa de Naciones Unidas para el Desarrollo la incluye como una de las dimensiones a valorar para determinar el desarrollo de los países empobrecidos en su Índice de Desarrollo Humano. Sin embargo, cuando se aborda el concepto de Educación para el Desarrollo (ED), se hace referencia a la actuación educativa que acontece entre los colectivos - personas, grupos, países "desarrollados"- que han tenido la suerte de tener más opciones para realizarse en su vida que la mayoría de la humanidad.

El concepto de ED, desde su aparición en los años 60, ha estado sujeto a una profunda discusión doctrinal (Ishii, 2003). La razón principal es que la disciplina padece una cierta indeterminación que le viene impuesta por dos frentes distintos: uno externo, referido a sus fronteras con otros campos del conocimiento asimilables (Sterling, 2001; Andreotti, 2007; Cordón et alii, 2012); y otro interno, concerniente al significado propio que se ha venido dando a la ED en cada país a lo largo de su evolución (Mesa, 2000; Boni, 2005; Ortega, 2008; en el caso español).

Respecto al primero de los argumentos, existen numerosas disciplinas que en cierta manera pueden agruparse dentro de una familia de educaciones que podríamos caracterizar por su sentido crítico y su fin emancipador: educación global, educación ambiental, educación para el desarrollo sostenible, educación para la paz y la no violencia, educación intercultural, educación para los Derechos Humanos, la dimensión global de la educación para la ciudadanía, etc.

Si analizamos estas disciplinas desde un plano horizontal, las fronteras que existen tanto entre sí como respecto a la Educación para el Desarrollo resultan muy difusas (Hicks, 2008). Pero si las analizamos desde un plano vertical, en numerosas ocasiones, en función de la corriente doctrinal en que se enmarque el autor que las propone, ha intentado instaurarse una cierta jerarquía entre dichas disciplinas, aspirando a situar una de ellas como el dominio más comprensivo y situando a las demás como expresiones sectoriales de la misma (Europe-wide Global Education Congress, 2002).

No es tarea del presente trabajo profundizar en este debate epistemológico, pero sí identificarlo para señalar que, cuando se hable de Educación para el Desarrollo 
y se aborde el segundo argumento, a saber, el de sus diferentes acepciones y su evolución a lo largo del tiempo, se hará referencia fundamentalmente al concepto de Educación para el Desarrollo que se maneja en la Unión Europea.

Esta concepción se encuentra recogida, fundamentalmente, en los documentos promovidos por las instituciones europeas: Consenso europeo sobre el desarrollo: La contribución de la educación y de la sensibilización en materia de desarrollo (Comisión Europea, 2007) y European Development Education Monitoring Report "DE Watch" (Krause, 2010). Adicionalmente, se harán algunas referencias al desarrollo doctrinal producido en España, cristalizado en la Estrategia Española de Educación para el Desarrollo (Ortega, 2008).

\title{
2.2. Conceptualizando la Educación para el Desarrollo
}

Circunscrito al ámbito europeo, el Consenso europeo sobre el desarrollo: la contribución de la educación y de la sensibilización identifica como objetivos de la ED

hacer posible que todos los europeos tengan a lo largo de su vida acceso a la posibilidad de sensibilizarse y de percibir los aspectos del desarrollo mundial y su importancia local y personal, y de ejercer sus derechos y responsabilidades como habitantes de un mundo interdependiente y cambiante, contribuyendo a hacerlo más justo y sostenible ${ }^{4}$.

Más concretamente, y siempre en palabras del mismo informe, la ED

\begin{abstract}
contribuye a erradicar la pobreza y a promover el desarrollo sostenible mediante el aumento de la sensibilización pública y de los planteamientos y actividades educativos basados en los valores de los derechos humanos, la responsabilidad social, la igualdad entre los sexos, y el sentimiento de pertenecer a un solo mundo; en las ideas y la percepción de las disparidades existentes entre las diversas condiciones de vida de los seres humanos y de los esfuerzos para superarlas; y en la participación en acciones democráticas que influyen en las situaciones sociales, económicas, políticas o medioambientales que afectan a la pobreza y al desarrollo sostenible ${ }^{5}$.
\end{abstract}

En el referido informe European Development Education Monitoring Report "DE Watch", Krause (2010) se adscribe a esta concepción de la ED, y refleja cómo la misma puede dar lugar a distintas interpretaciones del concepto, de las que resultaría una tipología de aproximaciones a la ED que el autor agrupa en cuatro grandes marcos:

\footnotetext{
${ }^{4}$ Comisión EUROPEA (2007), p. 6.

${ }^{5}$ Ibid., p. 6.
} 
- La ED como relaciones públicas: hace referencia a las actividades de comunicación dirigidas a incrementar el apoyo público a las intervenciones de cooperación. Puede ser realizada tanto por la administración, a modo de promoción de los buenos resultados alcanzados, como por las ONGD, con fines de captación de fondos. A pesar de que los actores que practican estas actividades las catalogan como ED, existe un amplio consenso (Centro Norte-Sur 2003, Comisión Europea 2007) que aboga por no reconocerlas como parte de la ED'.

- La ED como sensibilización: entendida como la diseminación pública de información sobre cuestiones más amplias en materia de desarrollo (ODM, desarrollo humano y sostenible, paz y desarrollo, comercio y desarrollo, globalización, etc.). Su objetivo es informar y sensibilizar sobre las causas de la pobreza, y tiene un marcado enfoque "top-down" en que el educando es visto más como receptor de la información que como protagonista de un proceso educativo de transformación personal.

- La ED como educación global: hace referencia a una educación orientada a transmitir las interdependencias del mundo globalizado, así como la responsabilidad del individuo y el impacto de sus acciones en el mismo. Tiene como objetivo el cambio en la actitud y en los comportamientos del individuo, promoviendo el compromiso y el activismo a favor de una mayor justicia global. Está centrada en la persona y su proceso de transformación social, con un enfoque normativo.

- La ED como mejora de las habilidades para la vida: consiste en potenciar el pensamiento crítico y analítico del educando, ofreciéndole las herramientas necesarias para analizar y comprender la complejidad del mundo que le rodea. Busca que el individuo sea capaz de reflexionar y actuar en consecuencia de forma autónoma $y$, en este sentido, se encuentra muy vinculado a corrientes educativas como el constructivismo. Está centrada en la persona y su proceso de transformación individual, con un enfoque sistémico.

Estas cuatro categorías no son tipos ideales, es decir, en la realidad y en el enfoque de ED que cada país o institución alberga coexisten elementos de varias, cuando no de todas ellas. Pero la clasificación provista por Krause (2010) permite establecer un mapa conceptual que se recoge en la tabla 1 :

${ }^{6}$ En el desarrollo doctrinal dado al concepto en España (Mesa, 2000; Baselga et alii, 2004; Boni, 2005), se ha recurrido con considerable repercusión a la noción de "generaciones" de ED. Esta sensibilización para la captación de fondos públicos ha sido definida como ED de primera generación, y también se considera que no forma parte de la ED tal y como es concebida hoy día. 


\section{TABLA I. Mapa conceptual de las diferentes tipologías de ED}

\begin{tabular}{|c|c|c|c|c|}
\cline { 2 - 5 } \multicolumn{1}{c|}{} & No reconocida como ED & \multicolumn{3}{c|}{ Reconocidas como ED } \\
\cline { 2 - 5 } & Relaciones Públicas & Sensibilización & Educación Global & Habilidades para la vida \\
\hline Temática & Cooperación al desarrollo & $\begin{array}{c}\text { Asuntos más amplios } \\
\text { del desarrollo }\end{array}$ & Interdependencia global & $\begin{array}{c}\text { Cuestiones éticas sobre } \\
\text { la sociedad global }\end{array}$ \\
\hline Objetivos & Apoyo público & $\begin{array}{c}\text { Incrementar la } \\
\text { sensibilidad ante la } \\
\text { realidad de la pobreza }\end{array}$ & $\begin{array}{c}\text { Promover una } \\
\text { acción responsable y } \\
\text { comprometida }\end{array}$ & $\begin{array}{c}\text { Desarrollo de una vida } \\
\text { plena y cambio social }\end{array}$ \\
\hline $\begin{array}{c}\text { Enfoque } \\
\text { educativo }\end{array}$ & Adoctrinamiento & $\begin{array}{c}\text { Suministro de } \\
\text { información }\end{array}$ & $\begin{array}{c}\text { Participativo, basado } \\
\text { en el proceso conozco- } \\
\text { comprendo-juzgo-actúo }\end{array}$ & $\begin{array}{c}\text { Empoderamiento, } \\
\text { enfoques críticos y } \\
\text { analíticos }\end{array}$ \\
\hline $\begin{array}{c}\text { Enfoque } \\
\text { pedagógico }\end{array}$ & Comercial & "Top-down" & Normativo, vivencial & Constructivista, sistémico \\
\hline $\begin{array}{c}\text { Visión del } \\
\text { educando }\end{array}$ & Objeto & Recipiente de la \\
información & $\begin{array}{c}\text { Protagonista de un } \\
\text { proceso de aprendizaje, } \\
\text { activista. }\end{array}$ & $\begin{array}{c}\text { Sujeto dinámico de } \\
\text { autoaprendizaje, agente } \\
\text { de cambio social. }\end{array}$ \\
\hline Contexto & Ayuda al desarrollo & Política de desarrollo & Globalización & Comunidad local y global \\
\hline
\end{tabular}

Fuente: Krause (2010), con algunas ampliaciones incluidas por los autores.

Refiriéndonos en concreto al caso español, la ED ha sido vista como un concepto amplio que, a lo largo de su evolución, ha estado sujeto a multitud de connotaciones y definiciones, en un discurrir ligado, por una parte, a la evolución de la educación y de las distintas teorías de aprendizaje (González, 2009) y, por otra, a la evolución que ha sufrido el concepto de desarrollo (Argibay, Celorio y Celorio, 1997; Baselga et alii, 2004).

De acuerdo a la clasificación ofrecida por Krause (2010), puede afirmarse que, en el ámbito español, está bastante extendida actualmente la concepción de la ED como un proceso de transformación personal del individuo, conjugando las definiciones de ED como educación global y como mejoramiento de las habilidades de la vida.

La Educación para el Desarrollo como proceso educativo contempla las siguientes fases en la constitución de la ciudadanía global: conocer la realidad del mundo global en que se vive y actúa, así como las causas de la pobreza existente (informar); tomar conciencia, de manera crítica y empática, de dichos problemas de pobreza y exclusión en el mundo y de la complejidad de la lucha contra éstos (sensibilizar); tomar conciencia del impacto que sobre dichos problemas globales 
tienen nuestras prácticas cotidianas (concienciar); capacitar a la ciudadanía para la toma de decisiones en esta línea en las instituciones en las que se trabaja, sean públicas o privadas, y para demandar a los gobiernos, sean del signo que sean, una política activa y comprometida en la construcción de un mundo que camine en la senda del desarrollo humano (comprometer).

En esta línea se enmarca la definición contenida en la Estrategia Española de Educación para el Desarrollo, cuando define a la ED como:

Un proceso educativo (formal, no formal e informal) constante encaminado, a través de conocimientos, actitudes y valores, a promover una ciudadanía global generadora de una cultura de la solidaridad comprometida en la lucha contra la pobreza y la exclusión así como con la promoción del desarrollo humano y sostenible?.

De esta manera se entiende que, desde el momento en que se sitúa en el centro a la persona, parece claro que el proceso de ED no puede desarrollarse exitosamente con la mera concatenación de acciones, aun cuando éstas sean llevadas a cabo por las mismas organizaciones, en los mismos espacios y ante los mismos educandos (Sianes et alii 2012). Bajo este paradigma de la ED como un proceso educativo centrado en la persona, la participación continua de las instituciones educativas y de sus docentes resulta trascendental. $Y$ entre estas instituciones, entendemos, debería situarse a la Universidad.

\subsection{La Universidad ante el desafio de la pobreza: sobre la pertinencia de integrar la Educación para el Desarrollo en el espacio universitario}

Del proceso de ED, ejecutado virtuosamente, cabe esperar que se genere una ciudadanía informada, sensibilizada, concienciada y comprometida en la lucha contra la pobreza. Sin embargo, para que dicha ciudadanía sea capaz de actuar responsablemente, promoviendo la transformación de las estructuras opresoras en otras más liberadoras, es necesaria una última dimensión: la competencia. De tal manera, resulta capital la concurrencia de las instituciones de educación formal, pues son las instituciones responsables de formar a la ciudadanía en las competencias necesarias para el ejercicio de una labor responsable en la sociedad. Y entre éstas, como institución que soporta en última estancia dicha formación en competencias, situamos a la Universidad.

7 Así, M.L. ORTEGa (2008) Estrategia de Educación para el Desarrollo de la cooperación española. Madrid: MAEC. 
Según el Programa de Naciones Unidas para el Desarrollo (PNUD 2010) la pobreza multidimensional afecta actualmente a más de 1.750 millones de personas, o lo que es lo mismo, casi un tercio de la población mundial refleja graves privaciones en salud, educación o nivel de vida. Al considerar junto a los tradicionales parámetros de ingresos económicos aquellos que reflejan otras privaciones que afectan a la vida de las personas, vemos que la pobreza es, hoy más que nunca, una dolorosa realidad ante la que no es posible permanecer impasible.

En un mundo globalizado, ninguna de las tres funciones tradicionalmente atribuidas a la Universidad ${ }^{8}$ puede resultar ajena a esta realidad de la pobreza multidimensional: tanto las funciones de docencia y de investigación como la de servicio a la sociedad, en cuanto elementos interrelacionados de una única función educativa, deberían considerar en su actuación la realidad de las mayorías excluidas.

A lo largo de la historia, han sido numerosas las corrientes que se han sumado a esta doctrina. En este artículo queremos rescatar, por su vigencia y lucidez, el posicionamiento de las universidades centroamericanas especialmente durante los años 70 y 80 del siglo pasado, representado en la figura de Ignacio Ellacuría, quien en el último discurso que pudo pronunciar", apenas diez días antes de que fuera asesinado en la UCA de El Salvador la madrugada del 16 de noviembre de 1989, sostenía:

Suele decirse que la Universidad debe ser imparcial. Nosotros creemos que no. La Universidad debe pretender ser libre y objetiva, pero la objetividad y la libertad pueden exigir ser parciales. $Y$ nosotros somos libremente parciales a favor de las mayorías populares porque son injustamente oprimidas y porque en ellas negativa y positivamente está la verdad de la realidad ${ }^{10}$.

Coincidimos con Samour (2007) al afirmar que la Universidad es una realidad política porque es una realidad histórica. Porque pertenecen a los asuntos de la "polis" y son de su interés las temáticas sobre las que investiga; porque son de

\footnotetext{
${ }^{8}$ Numerosos autores han publicado en esta misma revista artículos al respecto de la misión que una Universidad jesuita está llamada a desempeñar en la sociedad. Este artículo es especialmente deudor de los realizados por J.J. Romero (2007), J.M. Margenat (2008), M. Agúndez (2008) y J.A. SeneNt de FRUTOS (2010), así como de las ponencias realizadas por éstos y otros autores en las diferentes jornadas UNIJES, federación de centros universitarios de la Compañía de Jesús en España.

${ }^{9}$ El citado discurso tuvo lugar en Barcelona, con ocasión de la entrega del Premio Internacional Alfonso Comín a la Universidad Centroamericana José Simeón Cañas de El Salvador.

${ }^{10}$ Así, I. Ellacuría (1989), pp. 303-304.
} 
impacto social y político de primer nivel los contenidos y metodologías que conforman su docencia; y porque políticas son las instituciones que componen los órganos de gobierno de cada universidad, de capital importancia para determinar el desempeño de la misma.

Desde el momento en que la Universidad se asienta en un contexto histórico, la realidad no puede sino interpelarla para que contribuya a dar respuesta a sus desafíos. Y entre estos emerge de forma especialmente dolorosa la realidad de la pobreza y la exclusión que dan como resultado la falta de libertad para elegir la vida que tenemos razones para valorar (Sen, 2000).

En la medida en que, a día de hoy, la realidad económica, social y política de nuestras naciones sigue siendo privilegiada, entendemos que nuestras universidades se encuentran en una situación óptima para dedicar su atención no sólo al contexto local, sino para abrazar de forma extraordinariamente activa su cometido universal, enfrentando por tanto los desafíos globales de nuestro tiempo mediante el ejercicio de una "opción preferencial por los pobres".

Esta concepción emancipadora de la misión de la Universidad converge con la que se ha venido construyendo en el marco de la disciplina que hemos venido a denominar Educación para el Desarrollo (ED). Por tanto, si ya hemos señalado que la Universidad no puede permanecer impasible ante los desafíos que le plantea la situación mundial de pobreza y exclusión, es aún más cierto que la ED no puede prescindir de la Universidad si quiere completar virtuosamente su proceso transformador. Necesita de las competencias que la última institución del proceso de educación formal está en disposición de ofrecer. Cortina (2005:11) apunta en esta misma dirección, cuando afirma al respecto de la educación universitaria para la ciudadanía que el puro técnico-podríamos decir entonces- no es un buen profesional; tampoco lo es el incompetente bienintencionado.

Las universidades españolas, especialmente en los últimos años, han comenzado un proceso de asunción de responsabilidad en materias de cooperación y Educación para el Desarrollo. Prueba de ello son los sucesivos documentos que la Comisión Española Universitaria de Relaciones Internacionales (CEURI) de la Conferencia de Rectores de las Universidades Españolas (CRUE) ha elaborado, representando los hitos más reseñables la firma de la Estrategia de Cooperación Universitaria al Desarrollo del año 2000 (CEURI, 2000), y el Código de Conducta con que las universidades se dotan en materia de cooperación al desarrollo en el año 2006 (CEURI, 2006). 
Esta asunción de responsabilidad ha tomado dimensión legal desde que en 2001 la Ley 6/2001 de Universidades, de 21 de diciembre, (B.O.E. 24/12/2001), modificada por la Ley Orgánica 4/2007, de 12 de abril, (B.O.E. 13/04/2007) dispusiera:

La sociedad reclama a la Universidad del futuro una activa participación en sus procesos vitales. Por esta razón, la acción de la Universidad no debe limitarse a la transmisión del saber; debe generar opinión, demostrar su compromiso con el progreso social y ser un ejemplo para su entorno. La igualdad entre hombres y mujeres, los valores superiores de nuestra convivencia, el apoyo permanente a las personas con necesidades especiales, el fomento del valor del diálogo, de la paz y de la cooperación entre los pueblos, son valores que la Universidad debe cuidar de manera especial ${ }^{1}$.

No obstante, en la actualidad aún existen ciertas limitaciones para la labor universitaria en materia de desarrollo y cooperación, tanto debido a la falta de reconocimiento interno en la Universidad como, especialmente, por las dificultades para obtener la acreditación externa por parte de las entidades competentes ${ }^{12}$.

Estas reticencias no impiden que cada día más profesores y profesoras, en su labor diaria, ejerciten su labor docente e investigadora desde las claves de la lucha contra la pobreza. En el siguiente epígrafe nos detendremos en algunas propuestas y metodologías que, desarrolladas o recogidas por la ED, son susceptibles de facilitar y apoyar al profesorado en el ejercicio de dicha labor.

\section{La labor del profesorado universitario en el proceso de Edu- cación para el Desarrollo: razones para la esperanza}

En el apartado Il.2 hemos acabado por definir la ED como un proceso educativo constante, centrado en la persona, capaz de generar una ciudadanía con conciencia de vivir en un mundo globalizado, comprometida en la lucha contra la pobreza y la exclusión así como con la promoción del desarrollo humano y sostenible. En el centro de dicho proceso se encuentra el educando, la persona tomada de forma individual pero como parte indisoluble de una sociedad que ayuda a conformar y a la vez le trasciende.

${ }^{11}$ Ley Orgánica 4/2007, p. 16242.

${ }^{12}$ En 2011 se puso en marcha la Red Española de Estudios en Desarrollo (REEDES), formada por investigadores y docentes universitarios en el ámbito del desarrollo, con el objetivo declarado, entre otros, de constituir un grupo de interlocución eficaz que defienda el valor de la investigación y la docencia en temas de desarrollo y cooperación internacional para el desarrollo. 
Este proceso sólo puede producirse en el interior de la persona merced a una educación en actitudes y valores, tanto sociales como personales. A tal fin, es necesaria la implicación de las personas que están presentes a lo largo del proceso educativo para que éste pueda presentar resultados virtuosos.

Emerge así la importancia capital del profesorado, ya no exclusivamente como legatario y transmisor de conocimientos, sino como promotor y garante de este proceso educativo holístico. Es el profesorado el que, mediante su compromiso activo, está llamado a procurar el éxito en el proceso de ED a nivel universitario, gracias a la tutorización y al acompañamiento que puede brindar a sus estudiantes. Martínez, Buxarrais y Esteban caracterizan así esta labor:

Por un lado, el nuevo docente es el profesional encargado de enseñar a aprender la ciencia, de enseñar a gestionar el conocimiento de una forma significativa y con sentido personal para el estudiante, de crear auténticos escenarios de enseñanza y aprendizaje y, por otro, es el encargado de imprimir a los contenidos que enseña el carácter ético que hará que el estudiante sea un experto profesional y un buen ciudadano ${ }^{13}$.

Por su privilegiada posición en el aula, el profesorado está llamado a establecer los mecanismos que permitan configurar y poner en marcha dicho proceso educativo emancipador de manera adecuada. Afortunadamente, cuenta para ello a nivel personal, relacional e institucional, con una serie de factores y elementos que pueden facilitar el desempeño de esta labor, entre los cuales identificamos los que se detallan en los epígrafes sucesivos.

\section{I. Nivel institucional: la articulación del Espacio Europeo de Educación Superior}

Desde finales del siglo pasado, la educación superior en Europa está viviendo un proceso de convergencia hacia el Espacio Europeo de Educación Superior (EEES), articulado a través del denominado "proceso de Bolonia"14. Una de las principales

\footnotetext{
${ }^{13}$ Así, M. Martínez, M.R. Buxarrals y F. Esteban (2002), p. 34.

${ }^{14}$ En el presente artículo no vamos a profundizar en el origen y evolución de dicho proceso de convergencia; para quien desee profundizar en el argumento, remitimos al análisis que en la Revista Interuniversitaria de Formación del Profesorado realizase M. FeIXAS (2004).

Paralelamente, en Revista de Fomento Social encontramos un artículo del Padre M. AGúNDEZ (2008) en el que explora la sintonía entre el paradigma universitario Ledesma-Kolvenbach y el EEES, artículo del que son deudoras algunas de las reflexiones recogidas en este epígrafe. Así como la sugerente y reciente editorial titulado "Sentido de la formación ética en la universidad". RFS 67 (2012) 191-210.
} 
novedades que este proceso ha traído consigo es la puesta en marcha de un modelo de aprendizaje basado en competencias.

El concepto de "competencia" ha suscitado amplios debates a partir de su aparición en el ámbito de la educación superior, lo que ha llevado a que numerosos autores e instituciones hayan buscado una definición de consenso para el mismo. A efectos del presente artículo, nos sumamos a la definición dada por el proyecto Tuning ${ }^{15}$, que definió las competencias como

\begin{abstract}
una combinación de atributos (con respecto al conocimiento y sus aplicaciones, aptitudes, destrezas y responsabilidades) que describen el nivel o grado de suficiencia con que una persona es capaz de desempeñarlos resumidas en conocer y comprender (conocimiento teórico de un campo académico, la capacidad de conocer y comprender), saber cómo actuar (la aplicación práctica y operativa del conocimiento a ciertas situaciones) y saber cómo ser (los valores como parte integrante de la forma de percibir a los otros y vivir en un contexto social) $)^{16}$.
\end{abstract}

Este aprendizaje basado en competencias supone, a nuestro juicio, una magnífica vía para desarrollar contenidos y enfoques basados en el marco de la ED, fundamentalmente en las denominadas competencias transversales o genéricas. Entre 2004 y 2008 se implementaron en España los libros blancos ${ }^{17}$ llamados a servir de guía para que las distintas universidades desarrollasen las competencias específicas y transversales necesarias para la obtención de sus diferentes grados. Para no abordar el discurso a partir de una disciplina específica de conocimiento, haremos referencia solamente a las competencias transversales o genéricas, ya que además, los diferentes libros blancos han adoptado mayoritariamente las treinta competencias genéricas manifestadas en el proyecto Tuning. Estas son las que aparecen en la tabla 2:

\footnotetext{
${ }^{15}$ Liderado por la Universidad de Deusto y la Universidad de Groninga, el proyecto Tuning comenzó en el año 2000, cuando más de 100 universidades europeas iniciaron un proceso de investigación para determinar puntos de referencia comunes de cara al establecimiento de las competencias.

${ }^{16}$ Así, J. González y R. WagenaAr (2003), p. 80. Las redundancias en el texto están presentes en el original.

17 Los libros blancos son propuestas no vinculantes elaboradas para orientar a las universidades en el diseño de los diferentes títulos de grado adaptados al EEES.
} 


\section{TABLA 2. Competencias genéricas identificadas en el proyecto Tuning}

\begin{tabular}{|c|c|c|}
\hline Competencias Instrumentales & $\begin{array}{l}\text { Competencias } \\
\text { Interpersonales }\end{array}$ & Competencias Sistémicas \\
\hline $\begin{array}{l}\text { Capacidad de análisis y sín- } \\
\text { tesis. }\end{array}$ & $\begin{array}{l}\text { Capacidad crítica y auto- } \\
\text { crítica. }\end{array}$ & $\begin{array}{l}\text { Capacidad de aplicar los cono- } \\
\text { cimientos en la práctica. }\end{array}$ \\
\hline $\begin{array}{l}\text { Capacidad de organizar y } \\
\text { planificar. }\end{array}$ & Trabajo en equipo. & Habilidades de investigación. \\
\hline $\begin{array}{l}\text { Conocimientos generales bá- } \\
\text { sicos. }\end{array}$ & $\begin{array}{l}\text { Habilidades interperso- } \\
\text { nales. }\end{array}$ & Capacidad de aprender. \\
\hline $\begin{array}{l}\text { Conocimientos básicos de la } \\
\text { profesión. }\end{array}$ & $\begin{array}{l}\text { Capacidad de trabajar en } \\
\text { un equipo interdisciplinar. }\end{array}$ & $\begin{array}{l}\text { Capacidad para adaptarse a } \\
\text { nuevas situaciones. }\end{array}$ \\
\hline $\begin{array}{l}\text { Comunicación oral y escrita en } \\
\text { la propia lengua. }\end{array}$ & $\begin{array}{l}\text { Capacidad para comuni- } \\
\text { carse con expertos de otras } \\
\text { áreas. }\end{array}$ & $\begin{array}{l}\text { Capacidad para generar nue- } \\
\text { vas ideas (creatividad). }\end{array}$ \\
\hline $\begin{array}{l}\text { Conocimiento de una segunda } \\
\text { lengua. }\end{array}$ & $\begin{array}{l}\text { Apreciación de la diversidad } \\
\text { y multiculturalidad. }\end{array}$ & Liderazgo. \\
\hline $\begin{array}{l}\text { Habilidades básicas de manejo } \\
\text { del ordenador. }\end{array}$ & $\begin{array}{l}\text { Habilidad de trabajar en un } \\
\text { contexto internacional. }\end{array}$ & $\begin{array}{l}\text { Conocimiento de culturas y } \\
\text { costumbres de otros países. }\end{array}$ \\
\hline $\begin{array}{l}\text { Habilidades de gestión de la } \\
\text { información (habilidad para bus- } \\
\text { cary analizar información prove- } \\
\text { niente de fuentes diversas). }\end{array}$ & Compromiso ético. & $\begin{array}{l}\text { Habilidad para trabajar de } \\
\text { forma autónoma. }\end{array}$ \\
\hline Resolución de problemas. & & Diseño y gestión de proyectos. \\
\hline \multirow[t]{3}{*}{ Toma de decisiones. } & & $\begin{array}{l}\text { Iniciativa y espíritu empren- } \\
\text { dedor. }\end{array}$ \\
\hline & & Preocupación por la calidad. \\
\hline & & Motivación de logro. \\
\hline
\end{tabular}

Fuente: Elaboración propia basada en GonZÁlez y WAGENAAR (2003).

La adaptación de las titulaciones universitarias al EEES está brindando una oportunidad para definir competencias más cercanas al modelo de educación emancipadora que pretende la ED. Pero, para ello, coincidimos con Gehrig (2004) en que

sería muy conveniente no solamente copiar las competencias transversales del proyecto Tuning en los planes de estudios, sino ampliar e introducir algunas competencias claramente relacionadas con la ED [...]. Solo con la contemplación de la ED dentro de las competencias transversales se podría evitar una reducción de su importancia como ocurre en los espacios para futuros especialistas (postgrado) o como asignatura optativa 
que impartirían algunos expertos (en desconexión con el resto de las competencias). Las universidades solo pueden asumir su papel y su misión de ser transformadores de la sociedad si articulan institucionalmente un compromiso con la ED, una educación basada en valores para la ciudadanía globalizada ${ }^{18}$.

Según esto, querríamos plantear algunas propuestas para dos de los tres bloques de competencias identificados por el proyecto Tuning la saber: instrumentales, interpersonales y sistémicas). Estas propuestas, más que a agotar el argumento, aspiran a servir a título ilustrativo:

- Dentro del desarrollo de las competencias instrumentales: adaptada a las respectivas disciplinas de conocimiento, resultaría pertinente promover una comprensión crítica del fenómeno de la globalización y de su modelo de "maldesarrollo"19. Consideramos necesario seguir favoreciendo la comprensión por parte del alumnado universitario, de que el actual modelo de desarrollo es insostenible, además de favorecedor de injusticia, marginación y generador de una brecha cada vez mayor de pobreza y desigualdad. Esta toma de conciencia es clave para que, una vez que su formación superior esté finalizada, el ejercicio profesional se realice desde la clave de la responsabilidad ${ }^{20}$.

- Este aspecto también estaría presente en lo referente a las competencias sistémicas, a través de la reconfiguración de la competencia que aboga por una "preocupación por la calidad" hacia un compromiso por la sostenibilidad. El concepto de sostenibilidad es más poliédrico, ya que puede hacer referencia a la sostenibilidad social, económica, cultural o, como no, a la sostenibilidad ambiental. Pasar de un enfoque de calidad a un enfoque de sostenibilidad puede contribuir de manera más apropiada al modelo de desarrollo humano y sostenible.

\footnotetext{
${ }^{18}$ Así, R. Gehrig (2008), p. 5.

19 La primera vez que se utiliza el término "maldesarrollo" es en la obra de S. DASGUPTA "Peacelessness and Maldevelopment" de 1968, aunque probablemente la obra que popularizó el uso de este concepto fuera "Maldevelopment. Anatomy of a Global Failure", escrita por S. AmIN en 1990. En lengua castellana resultan claves las aportaciones, fundamentalmente, de J.M. TORTOSA (2001 y 2005).

20 En esta línea se pronunció el Consejo Estatal de Responsabilidad Social de las Empresas (CERSE), organismo promovido por el Ministerio de Trabajo que a través de su grupo de trabajo sobre Educación y Formación, al indicar a propósito de la formación universitaria en 2010: "Sería necesario reorientar los contenidos para que los valores y principios del nuevo paradigma del desarrollo sostenible y la responsabilidad, sobre el que no existen referencias expresas en la legislación educativa, adquiera una mayor relevancia e inspire de manera más efectiva los objetivos del sistema de educación superior" (CERSE, 2010: 9). De forma similar aparece reflejado en el documento "Universidad 2015" (ME, 2008).
} 
- En el desarrollo de las competencias interpersonales, consideramos pertinente que estas asuman los enfoques de género y de Derechos Humanos, en donde resultan muy valoradas por el alumnado las metodologías de aprendizaje de la ED basadas en el enfoque socio afectivo ${ }^{21}$.

La adopción de un enfoque de género en el desarrollo de las competencias interpersonales, además de enriquecer el proceso formativo a través del conocimiento de las distintas perspectivas, facilitará mecanismos para aumentar las capacidades de las mujeres, la autoestima de género, la autonomía y el poder de decisión sobre sus vidas en los ámbitos públicos y privados y en todos los espacios de participación social, política, económica y cultural, a través de su empoderamiento.

Por otra parte, el enfoque basado en Derechos Humanos contribuirá al conocimiento sobre los valores, principios y normas de los derechos y deberes de la ciudadanía, promoverá y fomentará los valores y actitudes que sustentan los Derechos Humanos y apoyará procesos en que se identifique "a los titulares de derechos y aquello a lo que tienen derecho, y a los correspondientes titulares de deberes y las obligaciones que les incumben" (NNUU, 2006: 15).

La adopción de estos enfoques exige un posicionamiento responsable (Manzano-Arrondo, 2011: 94), que quizá no encuentre en todo momento el apoyo institucional adecuado, pero que es necesario puesto que

hoy no podemos ya, ciertamente, conformarnos con la prudencia y la estrategia a la hora de trabajar por la vida en común, sino apostar por la justicia y por el reconocimiento de los derechos de los otros en la comunidad, con la esperanza de llegar a un consenso sobre intereses universalizables. Aquél debe ser, no obstante, no una mera tolerancia im-pasible, sino un reconocimiento com-pasivo que nace de las luchas por el reconocimiento 22 .

- Dentro de las competencias interpersonales: cabría reconsiderar aquellas que hablan de "compromiso ético" y "apreciación de la diversidad y la interculturalidad" bajo una perspectiva de ética y desarrollo. En este enfoque, consideramos que debería favorecerse en el estudiante el reconocimiento del pluralismo de nuestras sociedades más desde una perspectiva de interculturali-

${ }^{21}$ Como se explicitará más adelante, estas apreciaciones están basadas en la experiencia docente de los autores, tanto en grado como postgrado.

${ }^{22}$ Así, J.M. Margenat (2008), p. 653. 
dad que de multiculturalidad, promoviendo que contribuyan también mediante su ejercicio laboral a la construcción de una sociedad verdaderamente plural, de una sociedad que se asiente sobre una ética cívica que es, en palabras de Cortina (2000), aquella que se compone de unos mínimos compartidos entre las distintas ofertas de «máximos», entre las distintas propuestas de felicidad.

- Por último, planteamos la posibilidad de incluir una última competencia interpersonal: el ejercicio activo de una ciudadanía global. Tomando inspiración en la obra de pensadores de la teoría crítica como Houtart (2001), podemos identificar al ciudadano global como aquel que participa de una ciudadanía antisistémica, cuestionando la lógica imperante de la ortodoxia capitalista. Una ciudadanía portadora de utopías, que reaviva la esperanza, que se caracteriza por la búsqueda de alternativas a todos los niveles, tanto al nivel de las grandes conquistas políticas como al de la vida cotidiana, y que conquista los espacios públicos y aprovecha estos espacios para la articulación política.

3.2. Nivel personal: la adopción de enfoques metodológicos de la ED en el ejercicio de una pedagogía emancipadora

La ED en el ámbito de la educación universitaria permite al profesorado, siguiendo el correspondiente enfoque de las diferentes disciplinas universitarias, abordar con profundidad el proceso del desarrollo, así como las causas estructurales que generan y perpetúan la pobreza. Pero el ejercicio de este tipo de educación en el ámbito académico supone aplicar metodologías participativas capaces de crear también espacios de confrontación en el aula (Ortega, 2003: 67).

Con todas las salvedades necesarias, ya que no somos especialistas en pedagogía, pero merced a la experiencia de práctica docente adoptando el enfoque de de la $E D^{23}$, podríamos rescatar algunos enfoques metodológicos que pueden guiar al profesorado en el ejercicio de una pedagogía emancipadora:

- El enfoque socio-afectivo, en que el aprendizaje parte de las vivencias del educando cuando experimenta la realidad del otro. Se trata de un enfoque que aborda los temas de forma integral, no sólo a nivel cognitivo (aunque también), sino a un nivel emocional y empático que haga vivir en propia piel el tema que

${ }^{23}$ Estos enfoques han sido puestos en práctica con una buena valoración por parte del alumnado en la asignatura Desarrollo y Cooperación y en el Máster de Cooperación al Desarrollo y gestión de ONGD, que se vienen impartiendo en ETEA a partir de los años 2001 y 1999, respectivamente. 
se trabaja, haciéndolo sentir como propio. En cierta manera podríamos decir que responde al viejo aforismo que popularizase Benjamin Franklin, adaptando un célebre proverbio chino: Si me lo dices, lo olvido. Si me lo enseñas, lo recuerdo. Si me involucras, aprendo. La tarea del docente consistiría, por tanto, en crear un clima que fomente la construcción de grupo en un ambiente de aceptación, aprecio, confianza e integración y, a partir de ahí, simular estas vivencias sobre el tema que se quiere trabajar mediante una experiencia real o simulada: juego de rol, juego de simulación, lectura vivencial, etc. No se trata en absoluto de suprimir los contenidos sino, utilizando la expresión del maestro Freire, de romper con la concepción bancaria de la educación (Freire, 1988).

- El enfoque constructivista, heredero del modelo pedagógico desarrollado por Piaget, que hace referencia a una metodología en la que el papel del docente es promover que el estudiante se enfrente directamente y pueda resolver problemas reales del mundo que lo rodea. El alumnado construye a partir de lo que sabe: recupera, reconoce, contrasta, y al enfrentarse a la realidad mediante el trabajo con otros/as, aclara, mejora y complementa sus competencias previas. El papel del docente cambia de forma tal que se convierte en gerente de todo el proceso, respetando las concepciones preexistentes del estudiante y guiándolo mediante el uso del pensamiento crítico a construir alrededor de ellas.

- El enfoque holístico, según el cual el docente ha de promover en el educando una formación integral que atienda a todas las dimensiones del proceso de aprendizaje. Los Movimientos de Renovación Pedagógica (MRP) han actualizado las cuatro dimensiones identificadas Informe Delors (1997), diferenciando un total de cinco $^{24}$ : aprender a aprender o a construir conocimientos; aprender a hacer o a influir en el entorno; aprender a ser o adquirir valores; aprender a convivir o a relacionarnos; aprender a transformar o construir un mundo más justo.

Para traducir estos enfoques metodológicos hasta aquí ilustrados en propuestas concretas para el ejercicio de una pedagogía emancipadora, formulamos una enumeración no exhaustiva de elementos que, según nuestra experiencia, coadyuvan al proceso de ED:

\footnotetext{
${ }^{24}$ La enumeración es de elaboración propia, a partir de la definición de ED contenida en la web de la asociación educativa Barbiana, uno de los MRP más activos a nivel español: http://www.aebarbiana. org/?page id=384. Consultado el 23 de marzo de 2012.
} 
- Realizar actividades en el aula. El docente puede propiciar la creación de espacios de participación y reflexión dentro del aula utilizando toda una amplia variedad de materiales que numerosas ONGD y Movimientos de Renovación Pedagógica han elaborado a tal fin. Dichos materiales están accesibles en la web25, clasificados por objetivos de los mismos, públicos preferencialmente destinatarios, materiales necesarios para su ejecución, etc.

- Celebrar seminarios temáticos. Convenido que el primer paso de la ED consiste en romper el círculo de la indiferencia-ignorancia-indiferencia, es importante para el educando "poner rostro", ver la realidad de la pobreza de primera mano. Mediante el recurso a seminarios, el docente puede contar con la participación de los agentes de la sociedad civil directamente implicados en la ED: instituciones, autoridades, ONGD, organizaciones del Sur, etc. Actores que, merced a su experiencia, son capaces de sensibilizar y formar en enfoques de desarrollo humano global ofreciendo información de primera mano.

- Promover el aprendizaje de servicios de manera que éste se construya en un contexto de necesidades reales del entorno, tratando de mejorarlo. La inclusión en el modelo educativo del aprendizaje de servicios permite integrar aprendizajes relacionados con los valores y las dimensiones éticas de la persona a la formación universitaria de forma que contribuyan precisamente a la formación de ciudadanía competente en el sentido más completo (Martínez, 2008).

- Evaluar al alumnado de forma más adaptada a este proceso de aprendizaje. Numerosos pedagogos destacan que el aprendizaje y la evaluación necesitan ser coherentes. La investigación ha mostrado que la naturaleza de las tareas de evaluación influye en el enfoque que los estudiantes adoptan para aprender (Dochy et alii, 2002: 19). Sin hacer una revisión en profundidad del argumento, queremos destacar que ya están empezando a identificarse algunos métodos de evaluación que facilitan un adecuado proceso de ED, como podría ser el portafolio del alumno/a (Barberá, 2005).

${ }^{25}$ Consideramos especialmente útiles a tal fin los repositorios de la CONGDE (http://directorio-guia. congde.org/guiaderecursos/) y de la plataforma Docentes para el Desarrollo (http://docentesparaeldesarrollo.blogspot.com). A nivel interno, puede consultarse el canal de sensibilización de ETEA en YouTube (http://www.youtube.com/user/sensibilizacionETEA), consultas realizadas el 9 de mayo de 2012 
3.3. Nivel relacional: la búsqueda de apoyos y alianzas dentro y fuera de la Universidad

Tanto para la promoción y defensa de una Universidad con orientación social y solidaria, como para el desempeño de su labor docente e investigadora, el profesorado puede contar con diferentes aliados, tanto al interior de la institución como fuera de ésta.

Respecto a los agentes internos, cabe llamar la atención sobre la proliferación de estructuras solidarias ${ }^{26}$ que se han puesto en marcha, especialmente en los últimos 15 años, en las diferentes universidades españolas. A pesar de que su actividad es variada tanto en contenidos como en volumen, compartimos con Unceta (2007) la apreciación de que su constitución es un indicador importante del compromiso que la Universidad va adquiriendo con el impulso de actividades solidarias.

Suponen, pues, un magnífico punto de apoyo para el docente que quiere participar del proceso de ED: por un lado, de cara a su labor formativa, puede aprovechar los conocimientos, materiales y metodologías elaborados o sistematizados por las estructuras solidarias presentes en su Universidad; por otro lado, respecto a su labor investigadora, puede aprovechar las oportunidades de colaboración que estas estructuras le ofrecen -especialmente con otras universidades, pero también con otros agentes de la cooperación tanto en el "Norte" como en el "Sur"- para realizar una investigación interdisciplinar y de mayor impacto en la realidad de la pobreza.

De igual manera, el profesorado interesado por participar en el proceso de ED puede contar con el apoyo de diferentes actores externos a la Universidad.

En cierta manera, es una práctica bastante extendida contar con la participación de organizaciones e instituciones ajenas a la Universidad en las aulas, ya sea mediante la celebración de seminarios, jornadas o mesas redondas ${ }^{27}$.

${ }^{26}$ S. ARIAS Y A. SIMÓN (2004), p. 23, definen como estructura solidaria aquella estructura que, sea cual sea su origen o forma legal u organizativa, tiene como objetivos el estudio, la promoción, la formación, la investigación, la sensibilización y organización de actividades englobadas dentro de lo que podría denominarse el campo solidario y ejecutadas siempre desde el ámbito universitario. En esta consideración caben fundaciones, asociaciones, cátedras, institutos, y cualquier institución universitaria dedicada a la cooperación.

${ }^{27}$ Los ejemplos son numerosos a lo largo de la geografía española. En la formación de grado y postgrado en la que participan los autores de este artículo, por ejemplo, han participado en los últimos 
Sin embargo, la experiencia dice que encontrar ejemplos de una colaboración igualmente fluida en la labor de investigación es tarea más complicada, a pesar de que esa alianza es clave para que la Universidad contribuya de forma integral al proceso de ED. A tal fin, se antoja necesaria la integración de la investigación universitaria en el proceso de ED, a fin de dar rigor académico a las propuestas que ONGD y otros actores de la cooperación elevan a los agentes políticos para operar los cambios estructurales necesarios ${ }^{28}$. El entendimiento por parte de la comunidad universitaria con estos actores es condición ineludible para que acontezcan los cambios políticos pretendidos.

Una medida oportuna para favorecer esta colaboración sería la apertura de espacios de debate entre la comunidad investigadora universitaria y los agentes de la cooperación (administraciones central, autonómica y local, entidades sociales, ONGD, etc.). Estos espacios permitirían aprovechar los recursos humanos y materiales existentes de una manera coordinada.

Pero para que estos espacios sean productivos, sería pertinente dejar atrás algunas consideraciones que quizá hayan dificultado hasta ahora su constitución de forma más estable. Por un lado, resultaría conveniente que los agentes de la cooperación no acudiesen a la Universidad considerándola prioritariamente una prestadora de servicios, con recursos y capacidades privilegiadas para la investigación pero más ajena al proceso de cambio social. Y paralelamente, la Universidad debería velar por considerar y dar más voz a las organizaciones de la sociedad civil en sus órganos consultivos, viéndolas como un aliado estratégico en esta función social emancipadora. Encontrar y promover estos procesos de integración bidireccional podría contribuir al logro de una investigación que fomente el ejercicio de esta función.

años más de una decena de ONGD e instituciones del sistema de cooperación, tanto del "Norte" como del "Sur".

${ }^{28}$ Existen algunos ejemplos del potencial que esta colaboración puede tener. Por citar algunos ejemplos tratados en la literatura, la participación de Ingeniería Sin Fronteras en la Universidad de Oviedo o en la Politécnica de Madrid, o la de Acción Contra el Hambre en la Universidad Pública de Navarra. 


\section{Conclusiones}

Más allá de que la Universidad adopte o no una "opción preferencial por los pobres", es esperanzador pensar que desde el ejercicio de nuestra labor como profesorado universitario, sea en su dimensión docente o investigadora, podemos contribuir a que nuestro alumnado esté formado por personas informadas, sensibilizadas, concienciadas y comprometidas, con el conocimiento y las competencias adecuadas para luchar contra las desigualdades globales mediante el ejercicio de una ciudadanía global activa. En el presente artículo hemos visto que la Educación para el Desarrollo puede aportarnos algunas herramientas y metodologías que están empezando a mostrarse como facilitadoras para el desempeño de una pedagogía reflexiva, crítica y emancipadora.

Entendemos que, como parte indisoluble de la máxima institución de formación superior, no podemos permanecer ajenos a la realidad de pobreza y exclusión que separa nuestro mundo por un abismo de desigualdad. Quizá, no siempre encontraremos el contexto más favorable para ello, atrapados en ocasiones en un sistema de reconocimiento y acreditación que no parece premiar el cumplimiento de la que es nuestra función social como profesorado universitario. Pero ello no debería suponer un obstáculo para seguir desafiándonos a nosotros mismos, día a día.

En este sentido, no podemos dejar de recoger las esperanzadoras palabras del profesor Romero que nos invita a soñar:

La identidad nos viene dada por lo que somos, desde luego, pero sobre todo, por lo que queremos ser; más por nuestros proyectos que por nuestras realizaciones; más por nuestros sueños que por nuestra realidad ${ }^{29}$.

Cerramos este artículo con la esperanza de que alguna de las sugerencias en él contenidas pueda, al menos en cierta medida, animarnos a seguir en el camino y en la lucha.

${ }^{29}$ Así, J.J. ROMERO (2007), p. 396. 


\section{Bibliografía}

AGÚNDEZ, M. SJ (2008) "El paradigma universitario Ledesma-Kolvenbach", en Revista de Fomento Social n 252 (octubre-diciembre), pp. 603-631.

ANDREOTI, V. (2007) Research on discourses and practices related to the "global dimensión" in England, Notingham, Tesis doctoral.

Argibay, M., Celorio, G. y Celorio, J. J. (1997) Educación para el Desarrollo: El Espacio Olvidado de la Cooperación, Vitoria: Hegoa.

ARIAS, S. y SIMÓN, A. (2004) Las estructuras solidarias de las Universidades Españolas: organización y funcionamiento, Madrid: UAM - Fundación Telefónica.

BARBERÁ, E. (2005) "La evaluación de competencias complejas: la práctica del portafolio", en Educere, la Revista Venezolana de Educación, año 9, n 31, pp. 497-504.

Baselga, P., Ferrero, G., Boni, A., Ortega, M. L., Mesa, M., Nebreda, A., Celorio, J. J. y MONTERDE, R. (2004) La Educación para el Desarrollo en el Ámbito Formal, Espacio Común de la Cooperación y la Educación: Propuestas para una Estrategia de Acción Integrada. Valencia: UPV.

BoNI, A. (2005) La Educación para el Desarrollo en la enseñanza universitaria como una estrategia de la cooperación orientada al desarrollo humano. Valencia: UPV, tesis doctoral.

Centro Norte-Sur (2003) National Structures for the Organisation, Support and Funding of Development Education. A comparative analysis. Lisboa: GENE.

CEURI (2000) Estrategia de cooperación universitaria al desarrollo. Córdoba: CEURI-CRUE.

- (2006) Código de conducta de las universidades en materia de cooperación al desarrollo. Madrid: CEURI-CRUE.

COMISIÓN EUROPEA (2007) EU Report on Policy Coherence for Development. Bruselas: Commision Working Paper.

Consejo de Redacción (2012) "Sentido de la formación ética en la universidad" en Revista de Fomento Social n 266 (abril - junio), pp. 191-210. 
CONSEJO ESTATAL DE RESPONSABILIDAD SOCIAL, GRUPO DE TRABAJO SOBRE LA EDUCACIÓN, FORMACIÓN Y DIVULGACIÓN DE LA RSE (2010) La responsabilidad social, el desarrollo sostenible y el sistema de educación y formación, consultado el 4 de mayo de 2012 en http:// www.empleo.gob.es/es/sec trabajo/autonomos/economia-soc/RespoSocEmpresas/docs/110503 GRUPO DE TRABAJO RSE Y EDUCACION.pdf

CoRdón, M. R., SiAnes, A. M. y ORTEGA, M. L. (2012) Un recorrido en la educación para el desarrollo: a la búsqueda de un nuevo paradigma de educación global. Actas $8^{\circ}$ Congreso Internacional sobre Educación, Cultura y Desarrollo. Málaga: EUMED.

CoRtina, A. (2000) Ética mínima. Madrid: Editorial Tecnos S.A. (Primera edición, 1986).

- (2005) La misión de la Universidad: educar para la ciudadanía en el siglo XXI. Discurso de Inauguración de la Pontificia Universidad Católica De Valparaíso, año 2005, Consultado el 1 de mayo de 2012 en http://archivohistorico.ucv.cl/files/ discursos/Inauguracion 2005.pdf

DeloRS, J. (1997) La educación encierra un tesoro. Madrid: Santillana, Ediciones UNESCO (Primera edición, 1996).

Dochy, F., Segers, M., Dierick, S. (2002) "Nuevas Vías de Aprendizaje y Enseñanza y sus Consecuencias: una Nueva Era de Evaluación" en Revista de docencia universitaria, $2\left(n^{\circ} 2\right)$, pp. 13-30.

EllaCURíA, I. sJ (1989) "El desafío de las mayorías pobres", en Escritos Universitarios, pp. 296-306.

Europe-Wide Global Education Congress (2002) The Maastricht Declaration on Global Education. Consultada el 13 de marzo de 2012 en http://www.coe.int/t/ dg4/nscentre/ge/GE-Guidelines/GEgs-appl.pdf

FeIXAs, M. (2004) "De Bolonia a Berlín" en Revista interuniversitaria de formación del profesorado, 49, pp. 149-164.

FreIRE, P. (1988) Pedagogía del oprimido. Madrid: Siglo XXI editores (Primera edición, 1970).

GEHRIG, R. (2008) "Análisis de las competencias genéricas del modelo Aprendizaje basado en competencias en el diseño de las nuevas titulaciones del EEES como 
espacio transversal para la integración de elementos de la Educación para el desarrollo", en Actas del IV Congreso de Universidad y Cooperación al Desarrollo. Barcelona: UAB.

GonzÁlez, J. y WAGenAaR, R. (2003) Tuning Educational Structures in Europe. Informe Final. Fase Uno. Bilbao: Universidad de Deusto.

GonZÁlEZ, M. (2009) Una nueva oportunidad para la formación inicial del profesorado de Educación Secundaria. Revista de Educación, 350, pp. 57-78.

HICKS, D. (2008) Ways of seeing: The origins of global education in the UK. En Conference on Education for Sustainable Development/Global Citizenship. London: ITE.

HidAlgo CaPITÁn, A. L. (1998) El pensamiento económico sobre desarrollo: de los mercantilistas al PNUD. Huelva: Universidad de Huelva.

HOUTART, F. (2001) Sociedad civil globalizada: ¿̇la de abajo o la de arriba? Consultado el 16 de febrero de 2012: hitp://www.envio.org.ni/articulo/1081

ISHII, Y. (2003) Development Education in Japan: a comparative analysis of the contexts for its emergence, and its introduction into the japanese school system. Nueva York: Routledge Falmer.

KRAUSE, J. (2010) European Development Education Monitoring Report "DE Watch". Consultadoel 13/03/2012 en http://www.coe.int/t/dg4/nscentre/ge/DE Watch. pdf

Ley Orgánica 4/2007, de 12 de abril, por la que se modifica la Ley Orgánica 6/2001, de 21 de diciembre, de Universidades. Madrid: BOE núm. 89, pp. $16241-16260$.

Manzano-Arrondo, V. (2011) La Universidad Comprometida Consultado el 20/11/2012 en hittp://personal.us.es/vmanzano/LaUniversidadComprometida. pdf

MARGENAT, J. M. SJ (2008) lustitia: educar para una ciudadanía responsable, en Revista de Fomento Social n 252 (octubre-diciembre), pp. 651-669.

Martínez, M., Buxarrals, M. R. y Esteban, F. (2002) "La Universidad como espacio de aprendizaje ético" en Revista Iberoamericana de Educación, 29, pp. 17-43. 
MARTínez, M. (ED) (2008) Aprendizaje servicio y responsabilidad social de las universidades, Madrid. Octaedro.

ME, MINISTERIO de EDUCACIÓN (2010) Estrategia Universidad 2015. Consultado el 3 de mayo de 2012 en http://www.educacion.gob.es/dctm/eu2015/2011estrategia-2015-espanol.pdf? documentld=0901 e72b80910099

MESA, M. (2000) "La educación para el desarrollo: entre la caridad y la ciudadanía global" en Papeles de Cuestiones Internacionales, 70, pp. 11-26.

NACIONES UNIDAS, OfICINA DEL ALTO COMISIONADO dE NN.UU. PARA LOS DERECHOS HUMANOS (2006) Preguntas frecuentes sobre el enfoque de derechos humanos en la cooperación para el desarrollo. Nueva York: NN.UU.

ORTEGA, M. L. (2003) La educación para el desarrollo: una nueva perspectiva en el ámbito universitario" en Actas de la V Reunión de Economía Mundial. Sevilla: Universidad de Sevilla.

- (2008) Estrategia de Educación para el Desarrollo de la cooperación española. Madrid: Ministerio de Asuntos Exteriores y de Cooperación.

PNUD (2010) Informe sobre Desarrollo Humano 2010. Nueva York: PNUD.

ROMERO, J. J. sJ (2007) Misión de una Universidad jesuita: retos y líneas de futuro, en Revista de Fomento Social n 247 (julio-septiembre), pp. 393-418.

Samour, H. (2007) "Entrevista a Héctor Samour" en Revista Ibero Forum, Tomo 4, Vol. 1, 2007.

SEN, A. (2000) Desarrollo y Libertad. Bogotá: Editorial Planeta.

Senent de Frutos, J. A. (2010) "La función de la universidad en el pensamiento de Ignacio Ellacuría. Una visión desde nuestro contexto actual", en Revista de Fomento Social n 260 (octubre-diciembre), pp. 657-679.

Sianes, A. M., Cordón, M. R. y Ortega, M. L. (2012) "Development Education at University level: an ongoing process supported by structures. The 25 years experience in ETEA as a reference", en 6th International Technology, Education and Development Conference Proceedings. Valencia: INTED. 
Sobrino, J. sJ (1994) "Espiritualidad y seguimiento de Jesús" en ElLACURía, I. y SoBRINO, J. (edit.), Mysterium Liberationis. Conceptos fundamentales de la Teología de la Liberación, Tomo II. Madrid: Trotta.

SterLING, S. (2001) Sustainable Education. Re-visioning Learning and Change. Dartington: Green Books Ltd.

TORTOSA, J. M. (2001) El juego global - Maldesarrollo y pobreza en el capitalismo global. Barcelona: Icaria.

- (2005) Maldesarrollo y mal vivir. Pobreza y violencia a escala mundial. Quito: Editorial ABYA-YALA.

UNCETA, K. (2007) La cooperación al desarrollo en las universidades públicas españolas. Madrid: AECID. 